Gut and Liver, Vol. 11, No. 4, July 2017, pp. 474-480

REVIEW

\title{
Endoscopic Management of Pancreatic Fluid Collections in Children
}

\author{
Zaheer Nabi, Rupjyoti Talukdar, and D. Nageshwar Reddy \\ Asian Institute of Gastroenterology, Hyderabad, India
}

The incidence of acute pancreatitis in children has increased over the last few decades. The development of pancreatic fluid collection is not uncommon after severe acute pancreatitis, although its natural course in children and adolescents is poorly understood. Asymptomatic fluid collections can be safely observed without any intervention. However, the presence of clinically significant symptoms warrants the drainage of these fluid collections. Endoscopic management of pancreatic fluid collection is safe and effective in adults. The use of endoscopic ultrasound (EUS)-guided procedure has improved the efficacy and safety of drainage of pancreatic fluid collections, which have not been well studied in pediatric populations, barring a scant volume of small case series. Excellent results of EUS-guided drainage in adult patients also need to be verified in children and adolescents. Endoprostheses used to drain pancreatic fluid collections include plastic and metal stents. Metal stents have wider lumens and become clogged less often than plastic stents. Fully covered metal stents specifically designed for pancreatic fluid collection are available, and initial studies have shown encouraging results in adult patients. The future of endoscopic management of pancreatic fluid collection in children appears promising. Prospective studies with larger sample sizes are required to establish their definitive role in the pediatric age group. (Gut Liver 2017;11:474-480)

Key Words: Acute pancreatitis; Pancreatic fluid collection; Endosonography; Self expandable metallic stents

\section{INTRODUCTION}

Pancreatitis is not uncommon in pediatric age group. The incidence of acute pancreatitis (AP) appears to have increased over last two decades. ${ }^{1-3}$ Increased awareness among the primary care physicians/pediatricians and more referrals to tertiary care centers with in house pediatric gastroenterologists may be responsible for this rise. Though the mortality appears to be low in children and adolescents with AP, the morbidity is considerable. ${ }^{4}$ The etiologies of AP in children are different from that of adults. In adults, alcohol and gall stone related pancreatitis constitute the major causative factors, whereas trauma, infections, metabolic causes, drugs and congenital anomalies (such as choledochal cyst) are responsible for the same in children (Table 1). ${ }^{5-7}$

There is limited literature on pancreatitis (acute, recurrent or chronic) in children. The recent INSPPIRE (International Study Group of Pediatric Pancreatitis: In Search for a Cure) consortium defined AP in children if they fulfilled at least 2 out of 3 criteria-abdominal pain suggestive of, or compatible with AP (i.e., abdominal pain of acute onset, especially in the epigastric region), serum amylase and/or lipase activity at least three times greater than the upper limit of normal (international units/ liter) and imaging findings characteristic of, or compatible with AP (e.g., using ultrasonography, contrast enhanced computed tomography, endoscopic ultrasound, magnetic resonance imaging). ${ }^{8}$

Pancreatic fluid collections (PFCs) are a common complication of acute or chronic pancreatitis. After 4 weeks from the onset of AP, PFCs evolve into either walled of necrosis or pseudocyst as per the revised Atlanta classification. ${ }^{9}$ Walledoff necrosis is a mature, encapsulated collection of pancreatic and/or peripancreatic necrosis that has developed a well defined inflammatory wall (Fig. 1). Pancreatic pseudocyst is an encapsulated collection of fluid with a well defined inflammatory wall usually outside the pancreas with minimal or no necrosis (Fig. 2). ${ }^{9}$

The natural history of PFCs is largely unknown in pediatric patients. In a recent study, acute fluid collection developed in $58.6 \%$ of children with AP. However, pseudocyst developed in $38 \%$ and drainage was required in only $26.4 \%$ of these. ${ }^{10}$ Asymptomatic PFCs can be managed conservatively. However, symptomatic PFCs require drainage.

In the following review we will discuss the increasing role of endoscopy in the management of PFCs in children.

Correspondence to: D. Nageshwar Reddy

Asian Institute of Gastroenterology, 6-3-661, Somajiguda, Hyderadad 500-082, India

Tel: +91-40-23378888, Fax: +91-40-23324255, E-mail: aigindia@yahoo.co.in

Received on March 17, 2016. Revised on July 4, 2016. Accepted on July 6, 2016. Published online May 19, 2017

pISSN 1976-2283 eISSN 2005-1212 https://doi.org/10.5009/gnl16137

@) This is an Open Access article distributed under the terms of the Creative Commons Attribution Non-Commercial License (http://creativecommons.org/licenses/by-nc/4.0) which permits unrestricted non-commercial use, distribution, and reproduction in any medium, provided the original work is properly cited. 
Table 1. Etiologies of Acute Pancreatitis in Children versus Adults

\begin{tabular}{|c|c|c|}
\hline Etiology & Percent & Description \\
\hline \multicolumn{3}{|l|}{ Children } \\
\hline Systemic & $3.5-51$ & $\begin{array}{l}\text { Hemolytic-uremic syndrome, Reye's syndrome, Kawasaki disease, } \\
\text { IBD, HSP, SLE }\end{array}$ \\
\hline Biliary & $5.4-20$ & Gall stones/sludge, choledochal cyst \\
\hline Anatomic & $1.5-11.5$ & Pancreas divisum, $\mathrm{APBU}$ \\
\hline Trauma & $6.5-46$ & Blunt injury \\
\hline Familial & $3-18$ & \\
\hline Cystic fibrosis & $0.4-3$ & \\
\hline Metabolic & $0.7-7$ & DA, hyperlipidemia, OA, hypercalcemia \\
\hline Drug & $3.2-30$ & Sodium valproate, thiopurines, thiazides, corticosteroids \\
\hline Other & $2-26$ & Viral*, post-ERCP \\
\hline Idiopathic & $8-35$ & \\
\hline \multicolumn{3}{|l|}{ Adult } \\
\hline Alcohol & $10-14$ & \\
\hline Biliary & $44-55$ & \\
\hline Metabolic & $1-10$ & Hyperlipidemia, hypercalcemia \\
\hline Idiopathic & $23-30$ & \\
\hline Others & $19-20$ & $\begin{array}{l}\text { Post-ERCP, sphincter of Oddi dysfunction, ampullary tumors, } \\
\text { hypercalcemia, and systemic lupus erythematosus }\end{array}$ \\
\hline
\end{tabular}

IBD, inflammatory bowel disease; HSP, Henoch-Schönlein purpura; SLE, systemic lupus erythematosus; APBU, anomalous pancreaticobiliary union; DA, diabetic acidosis; OA, organic academia; ERCP, endoscopic retrograde cholangiopancreatography.

*Epstein-Barr virus, mumps, measles, rubella, cytomegalovirus, influenza A.

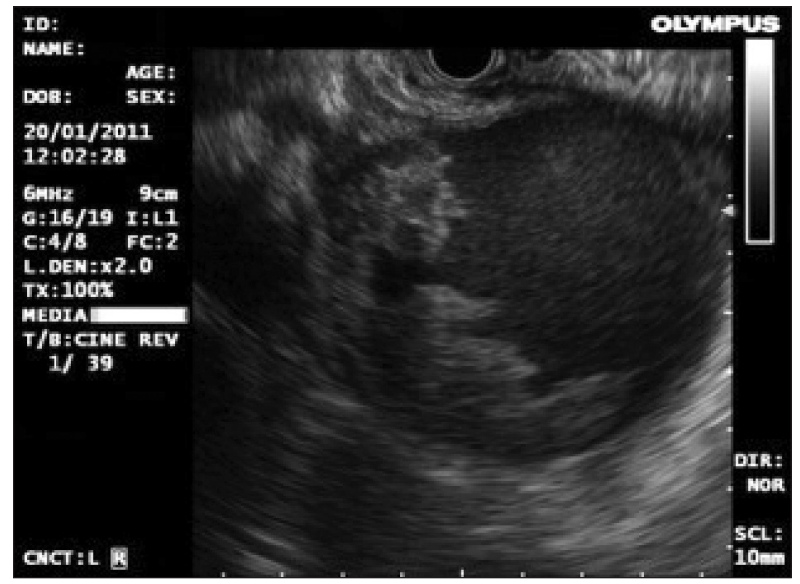

Fig. 1. Endoscopic ultrasound image of walled off necrosis. Note the debris inside the fluid collection.

\section{ENDOSCOPIC MANAGEMENT OF PFCs}

Traditionally, surgical or percutaneous drainage has been utilized for PFCs. However, these modalities carry significant morbidity. Percutaneous drainage is also associated with the development of external pancreatic fistula that may be difficult to manage. Therefore, there is an unmet need for a minimally

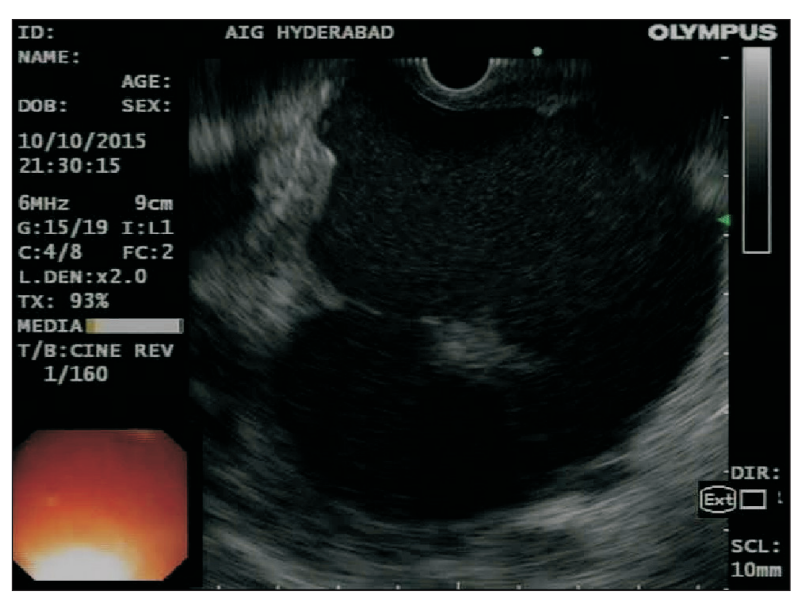

Fig. 2. Endoscopic ultrasound image of a pseudocyst. Note the clear contents of fluid collection.

invasive, safe and efficacious treatment modality for PFCs in children.

Endoscopic drainage of PFCs has emerged as a safe and efficacious treatment option in adults. ${ }^{11,12}$ There is emerging data regarding the feasibility, efficacy and safety of endoscopic drainage of PFCs in children as well. ${ }^{13-19}$

Endoscopic drainage can be accomplished either transmurally 
Table 2. Comparison of Techniques of Endoscopic Drainage of Pancreatic Fluid Collection

\begin{tabular}{|c|c|c|}
\hline & Advantage & Drawback \\
\hline Conventional transmural drainage & Minimally invasive, rapid recovery & $\begin{array}{l}\text { Blind approach, risk of bleed and perforation, } \\
\text { luminal bulge required, PD abnormality overlooked }\end{array}$ \\
\hline Transpapillary drainage & $\begin{array}{l}\text { Physiological route of drainage, } \\
\text { ductal leaks can be bridged. }\end{array}$ & $\begin{array}{l}\text { Effective only for small and communicating } \\
\text { pseudocysts, cyst infection, stent induced PD } \\
\text { changes }\end{array}$ \\
\hline EUS-drainage & $\begin{array}{l}\text { More effective, luminal bulge not required, } \\
\text { intervening vessels can be avoided. }\end{array}$ & $\begin{array}{l}\text { Expertise required, PD abnormality overlooked, } \\
\text { difficult in smaller children }(<5 \mathrm{yr})\end{array}$ \\
\hline Endoscopic stents-plastic & $\begin{array}{l}\text { Cheap, no risk of impaction, can be placed for } \\
\text { longer duration. }\end{array}$ & Smaller lumen, easily get clogged. \\
\hline Endoscopic stents-metal & $\begin{array}{l}\text { Wider lumen, less chances of occlusion, } \\
\text { allows necrosectomy. }\end{array}$ & Costly, risk of stent impaction \\
\hline
\end{tabular}

PD, pancreatic duct; EUS, endoscopic ultrasound.

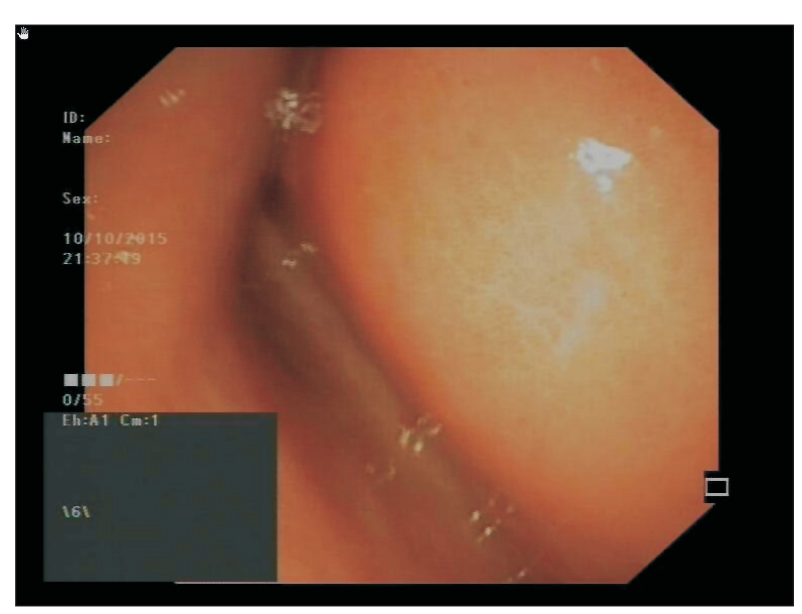

Fig. 3. Endoscopic image showing a bulge due to pancreatic fluid collection in the stomach.

or by transpapillary route. Transmural drainage can be accomplished with or without the guidance of EUS (Table 2).

Transpapillary drainage: This method is used when a small pseudocyst is seen to be communicating with the pancreatic duct; and can be performed under standard endoscopic retrograde cholangiopancreatography (ERCP) setting. ${ }^{20,21}$ Endoscopic sphincterotomy followed by pancreatic ductal stenting is done to bridge the leak and divert pancreatic juice away from the cystic cavity. Alternatively, the stent can be placed into the cyst cavity. However, bridging the ductal disruption or leak gives the best result. Even if bridging the leak may not be feasible, just keeping the stent across the sphincter could confer some benefit. The advantages of transpapillary drainage are minimum risk of bleeding and perforation. Moreover, the pancreatic duct can be analyzed for any stricture or calculi. The major drawbacks with transpapillary drainage include potential for cyst infection, suboptimal drainage of large collections and stent induced de novo pancreatic ductal changes. ${ }^{22}$

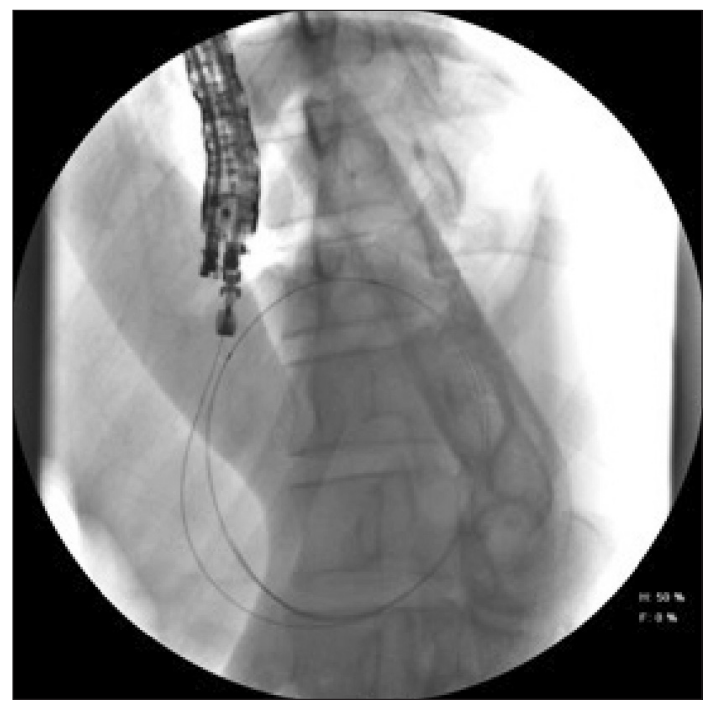

Fig. 4. Fluoroscopy image depicting the coiling of guide wire inside the cyst cavity.

\section{TRANSMURAL DRAINAGE}

The procedure can be performed under moderate sedation. Prophylactic antibiotics are routinely administered starting on the day of procedure and revised subsequently as per the fluid culture-sensitivity report. Transmural endoscopic drainage of PFC requires an extrinsic bulge in the stomach or duodenum (Fig. 3). It can also be achieved via trans esophageal route in select cases. ${ }^{23}$ The cystogastric wall is punctured by a regular fine needle aspiration needle (19 gauge) and cyst fluid aspirated for visual inspection and analysis (amylase and microbial culturesensitivity). The guide wire with hydrophilic tip (0.025", 450 $\mathrm{cm}$ ) is coiled inside the cyst cavity and can be visualized fluoroscopically (Fig. 4). The cystogastric tract is then dilated over the guide wire with $6 \mathrm{~F}$ cystotome followed by small caliber balloon dilatation (Hurricane, $6 \mathrm{~mm}$ ) (Fig. 5). In the final step cystogas- 
tric double pigtail plastic stents are placed (usually 7F) (Fig. 6). The rapid flow of PFC content through the stent into stomach is considered as marker of technical success.

Endoscopic drainage of PFCs is a safe procedure. The reported complications in adult patients include-bleeding, perforation and sepsis. ${ }^{12}$ However, these complications are uncommon. Unfortunately, there is scant literature on endoscopic drainage of PFCs in children and adolescents. The published literature is in the form of case reports and small case series only (Table 3). The results in these series are nevertheless promising and warrant further studies.

\section{FOLLOW-UP AFTER ENDOSCOPIC DRAINAGE}

The children undergoing endoscopic drainage are followed at regular intervals to look for clinical and radiological response. The stents are removed (usually after 4 to 8 weeks) once resolution of the PFC is documented by imaging. Magnetic resonance cholangiopancreaticogram is usually performed prior to removal of the stent to delineate pancreatic ductal anatomy. Endoscopic retrograde pancreaticogram and pancreatic ductal stenting is

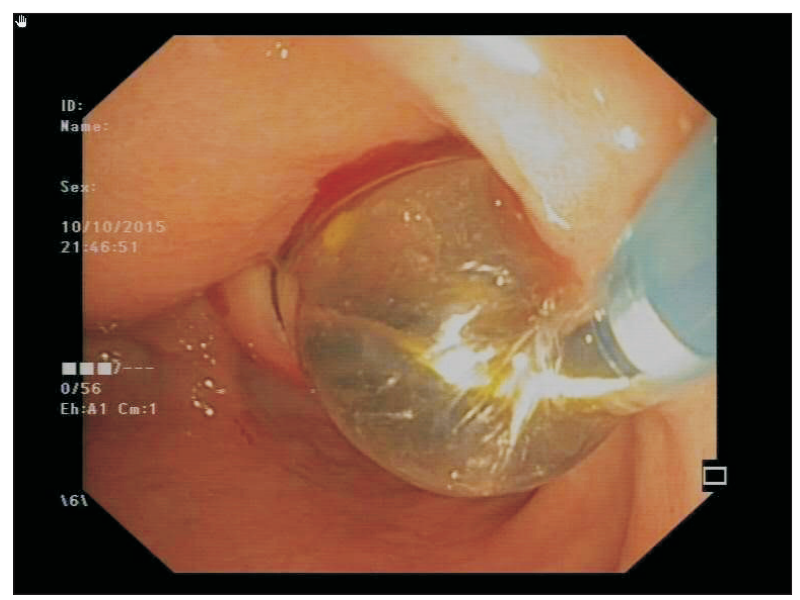

Fig. 5. Endoscopic image showing balloon dilatation of the cystogastric tract. performed in cases of leaks or pancreatic ductal disruptions (Fig. 7).

\section{EUS-GUIDED DRAINAGE OF PFC}

EUS-guided drainage of pseudocyst was initially reported by Grimm et al. ${ }^{24}$ in 1992 and later by Wiersema in $1996 .^{25}$ EUS was used to mark the optimum site for drainage and subsequently a therapeutic duodenoscope was used to complete the drainage procedure. Since then, the technique has evolved and now the complete procedure can be accomplished by echoendoscope itself. In the present era, EUS-guided drainage is the preferred modality for PFCs drainage in adult patients. There is emerging role of EUS as a diagnostic as well as therapeutic modality in pediatric pancreaticobiliary disorders. ${ }^{26}$

EUS-guided drainage adds to the safety and efficacy of the drainage procedure as intervening vessels can be visualized and avoided during puncture of the PFC. Other advantages of EUSguided drainage of PFCs include-assessment of the volume of

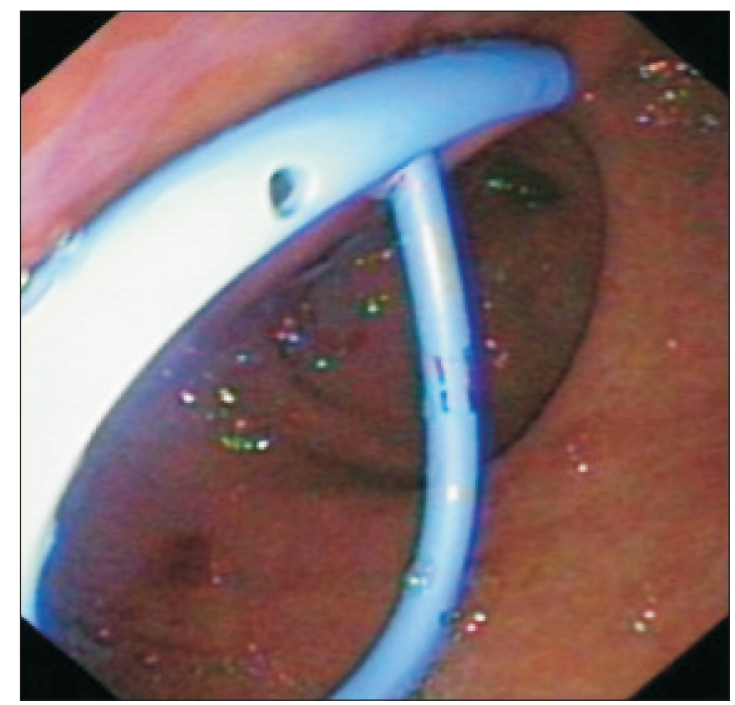

Fig. 6. Endoscopic image after cystogastric deployment of a double pigtail plastic stent.

Table 3. Case Series of Endoscopic Drainage of Pancreatic Fluid Collection in Children

\begin{tabular}{|c|c|c|c|c|c|}
\hline Study & No. of children & Age, yr & Technical and clinical success, $\%$ & Complications & Follow-up, median, mo \\
\hline Patty et al. ${ }^{13}$ & 3 & $2.5,3,11$ & 100 & None & 24 \\
\hline Al-Shanafey et al. ${ }^{14}$ & 4 & $11^{*}$ & 100 & None & 26 \\
\hline Makin et al. ${ }^{15}$ & 7 & $11.7^{*}$ & 71 & $\begin{array}{l}\text { Stent migration }(\mathrm{n}=1), \\
\text { cystogastrostomy }(\mathrm{n}=1)\end{array}$ & 18 \\
\hline Breckon et al. ${ }^{16}$ & 2 & 4,10 & 100 & None & 6 \\
\hline Nouira et $a l .{ }^{17}$ & 2 & 7,13 & 100 & None & $3-36$ \\
\hline Haluszka et al. ${ }^{18}$ & 2 & 8,16 & 100 & Sepsis $(n=1)$ & 12 \\
\hline Sharma and Maharshi ${ }^{19}$ & 9 & $9.6^{*}$ & 100 & None & 68 \\
\hline
\end{tabular}

*Median. 


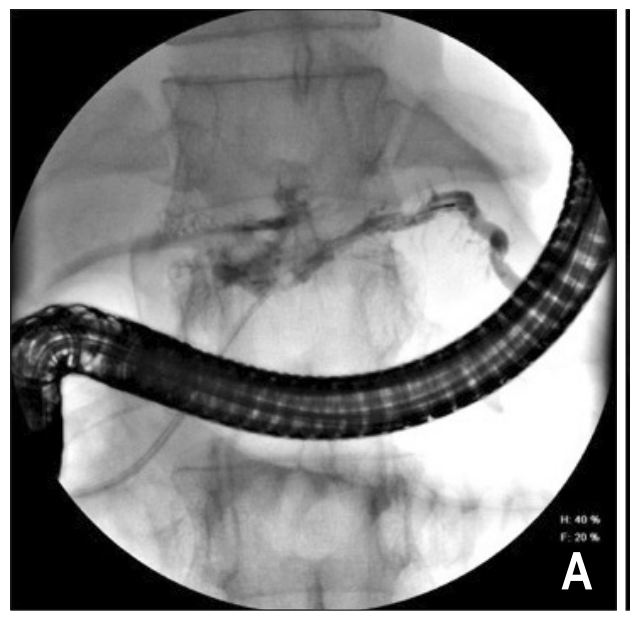

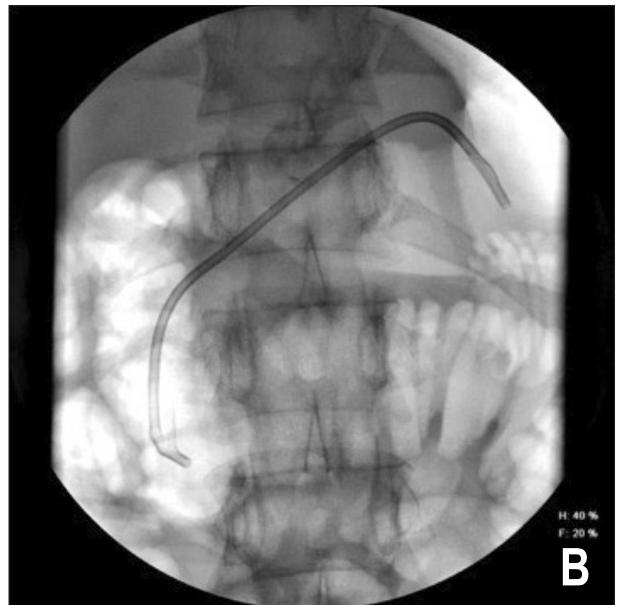

Fig. 7. (A) Endoscopic retrograde pancreaticogram depicting partial pancreatic ductal disruption with a leak from the mid body. (B) Endoscopic retrograde pancreaticography and successful bridging of a pancreatic ductal leak by plastic stent.

Table 4. Case Series of Endoscopic Ultrasound-Guided Drainage of Pancreatic Fluid Collection in Children

\begin{tabular}{lccccc}
\hline \multicolumn{1}{c}{ Study } & No. of children & Age, median, yr & Technical and clinical success, \% & Complications & Follow-up, median, mo \\
\hline Jia et al. $^{23}$ & 2 & 13 & 100 & None & 6 \\
Jazrawi et al. $^{27}$ & 10 & 13.5 & 100 & None & 6 \\
Ramesh $^{28}$ & 7 & 8.4 & 100 & None & 34 \\
Kim et al. $^{29}$ & 5 & 12 & 100 & Delayed bleed $(\mathrm{n}=1)$ & 6 \\
Trevino et al. $^{30}$ & 4 & 10 & 100 & None & 9 \\
Lakhtakia $^{31}$ & 4 & 9.5 & 100 & Bleed (n=1) & 3 \\
\hline
\end{tabular}

PFC contents and distance of PFC from lumen, with a linear array echoendoscope, in the absence of a bulge. . $^{32,33}$

The basic technique of EUS guided-drainage is the same as described above. The optimal site for drainage is selected under EUS guidance and the subsequent steps are carried in the usual manner as in conventional transmural endoscopic drainage.

Jazrawi et al. ${ }^{27}$ evaluated the safety and efficacy of EUS-guided drainage of pancreatic pseudocysts with plastic stents in ten children. The mean age was 11.8 years and all the pseudocysts could be successfully drained. In another retrospective analysis of seven children, who underwent EUS-guided drainage of PFCs with plastic stents, technical and clinical success was achieved in all the children. ${ }^{28}$ Our group recently reported EUS guided trans-esophageal drainage of pseudocysts in four children. There were no major complications and both technical and clinical success was achieved in all the children. ${ }^{31}$

Two randomized controlled trials compared conventional drainage with EUS-guided drainage of PFCs in adult patients. Technical success was higher and complications lower in the EUS-guided drainage group. Moreover, PFCs that could not be drained with conventional method, were successfully drained by EUS-guided approach. ${ }^{32,33}$

Excellent safety and efficacy of EUS-guided drainage in adult patients needs to be verified in children and adolescents as well. At present, the available literature in pediatric age group is in form of small case series and case reports (Table 4). ${ }^{23,27-31}$

\section{METAL STENTS FOR PFCs}

Traditionally, double pigtail plastic stents have been used for endoscopic cystoenteric drainage. However, due to smaller caliber of the stent and the presence of debris in the PFC cavity, plastic stents may get clogged, leading to complications like nonresolution and infection of the PFC. Recently, dedicated fully covered self expanding metal stents (FCSEMS) have been designed and used with encouraging results in adult patients with PFCs. ${ }^{34-37}$ These FCSEMS are equipped with unique properties like lumen apposition and have flared ends that prevent stent migration (Fig. 8).

FCSEMS provide larger diameter for efficient drainage of cyst contents as well as enable endoscopic necrosectomy when required (Fig. 9). The safety and efficacy of FCSEMS for EUSguided drainage of PFCs in children is not known. Giefer and Balmadrid $^{38}$ reported the use of lumen apposing stent (AXIOS; Boston Scientific, Marlborough, MA, USA) in a 11-year-old girl with large walled off necrosis. The authors also performed three sessions of endoscopic necrosectomy. The metal stent was removed after 2 weeks and two 7F plastic stents were placed. Another recent case series (abstract form) described the use of FCSEMS in pediatric PFCs. The authors described the use of novel lumen apposing SEMS in five children (mean age, 7.4 years; range, 3 to 16 years) with PFCs (pseudocysts, 3; walled off necrosis, 3). The mean size of PFCs was $8.7 \mathrm{~cm}$ (range, 5.5 to 


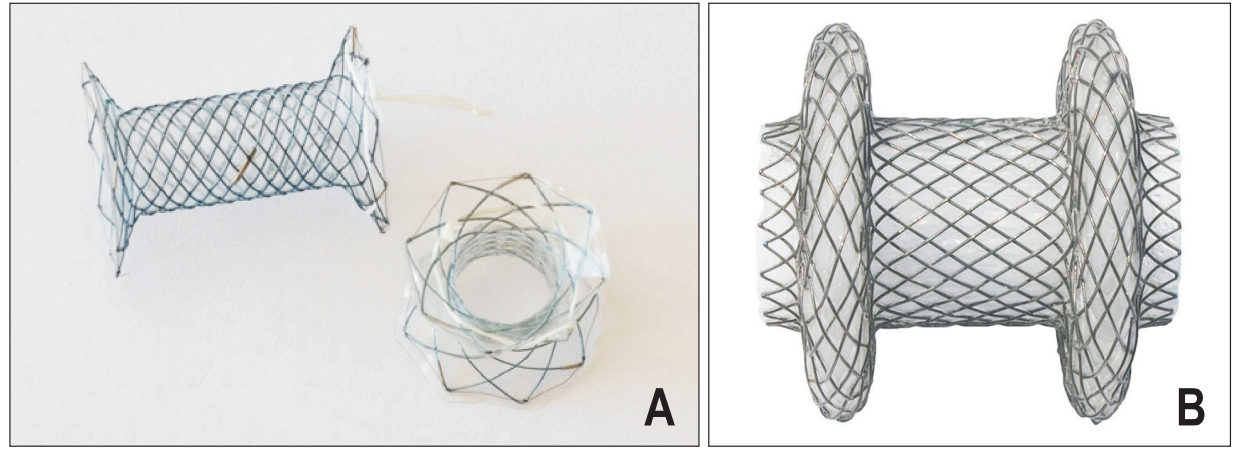

Fig. 8. (A) Fully covered metal stent with flared ends designed for the drainage of pancreatic fluid collection $\left(\right.$ Nagi $^{\mathrm{TM}}{ }^{\mathrm{M}}$; TaeWoong Medical Co., Ltd.). (B) Fully covered lumen apposing metal stent designed for the drainage of pancreatic fluid collection (Axios; Xlumena).

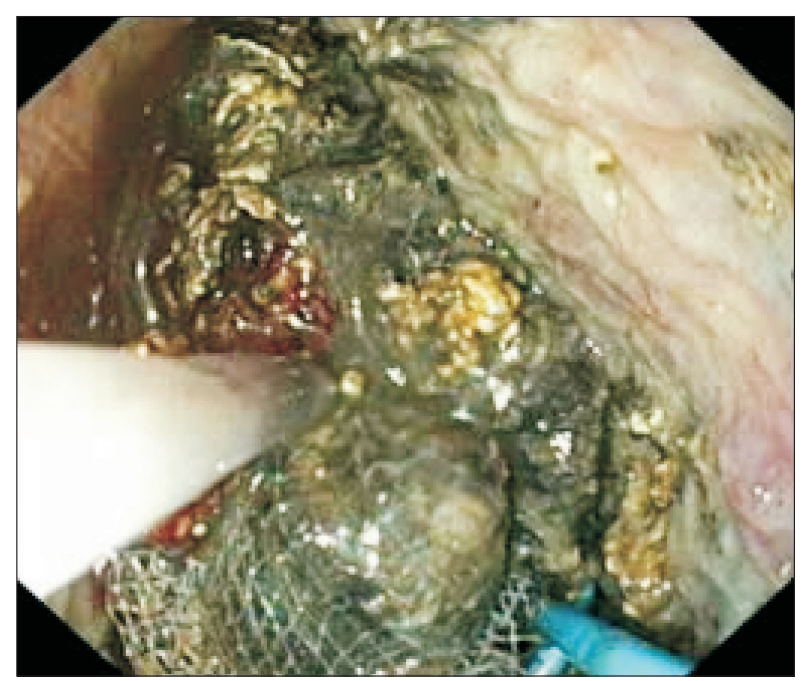

Fig. 9. Endoscopic necrosectomy-endoscopic view of cyst cavity with necrotic debris being removed by a standard Roth Net.

$14.0 \mathrm{~cm}$ ). Endoscopic necrosectomy was performed in two children. Technical and clinical success was 100\%. There were no complications, stent migration or stent occlusion. ${ }^{39}$

These studies suggest the feasibility of metal stents for PFCs in children. However, more studies with larger sample size and longer follow up are required to draw firm conclusions on the use of these novel SEMS in pediatric PFCs.

\section{CONCLUSIONS}

The incidence of AP is increasing in pediatric population. It carries significant morbidity. Development of PFCs is the most common complication of severe AP. The management of PFCs should be individualized. The nature of PFCs should be characterized as pseudocyst or walled-off necrosis as treatment outcomes may differ. Majority of acute fluid collections do not require any intervention as they resolve spontaneously. Endoscopic drainage of PFCs has established its roots in adults. However, it is still emerging in pediatric population and the literature is sparse. Based on currently available data, EUS guided drainage of PFCs appears to have immense utility in children, and therefore needs to be tested in optimally designed clinical trials with large sample sizes. Early reports of novel FCSEMS are encouraging. However, larger prospective studies are required to establish their efficacy in pediatric population.

\section{CONFLICTS OF INTEREST}

No potential conflict of interest relevant to this article was reported.

\section{REFERENCES}

1. Nydegger A, Heine RG, Ranuh R, Gegati-Levy R, Crameri J, Oliver MR. Changing incidence of acute pancreatitis: 10-year experience at the Royal Children's Hospital, Melbourne. J Gastroenterol Hepatol 2007;22:1313-1316.

2. Morinville VD, Barmada MM, Lowe ME. Increasing incidence of acute pancreatitis at an American pediatric tertiary care center: is greater awareness among physicians responsible? Pancreas 2010;39:5-8.

3. Pant C, Deshpande A, Olyaee M, et al. Epidemiology of acute pancreatitis in hospitalized children in the United States from 20002009. PLoS One 2014;9:e95552.

4. Goday PS, Wakeham M, Kuhn EM, Collins MM, Werlin SL. Acute pancreatitis in the pediatric intensive care unit. J Pediatr Gastroenterol Nutr 2015;61:108-112.

5. Lowe ME, Greer JB. Pancreatitis in children and adolescents. Curr Gastroenterol Rep 2008;10:128-135.

6. Zheng Y, Zhou Z, Li H, et al. A multicenter study on etiology of acute pancreatitis in Beijing during 5 years. Pancreas 2015;44:409-414.

7. Rashidi M, Røkke 0. Prospective evaluation of the cause of acute pancreatitis, with special attention to medicines. World J Gastroenterol 2016;22:2104-2110.

8. Morinville VD, Husain SZ, Bai H, et al. Definitions of pediatric pancreatitis and survey of present clinical practices. J Pediatr Gastroenterol Nutr 2012;55:261-265.

9. Banks PA, Bollen TL, Dervenis C, et al. Classification of acute pancreatitis 2012: revision of the Atlanta classification and definitions by international consensus. Gut 2013;62:102-111. 
10. Bolia R, Srivastava A, Yachha SK, Poddar U, Kumar S. Prevalence, natural history, and outcome of acute fluid collection and pseudocyst in children with acute pancreatitis. J Pediatr Gastroenterol Nutr 2015;61:451-455.

11. Cahen D, Rauws E, Fockens P, Weverling G, Huibregtse K, Bruno M. Endoscopic drainage of pancreatic pseudocysts: long-term outcome and procedural factors associated with safe and successful treatment. Endoscopy 2005;37:977-983.

12. Hookey LC, Debroux S, Delhaye M, Arvanitakis M, Le Moine O, Devière J. Endoscopic drainage of pancreatic-fluid collections in 116 patients: a comparison of etiologies, drainage techniques, and outcomes. Gastrointest Endosc 2006;63:635-643.

13. Patty I, Kalaoui M, Al-Shamali M, Al-Hassan F, Al-Naqeeb B. Endoscopic drainage for pancreatic pseudocyst in children. J Pediatr Surg 2001;36:503-505.

14. Al-Shanafey S, Shun A, Williams S. Endoscopic drainage of pancreatic pseudocysts in children. J Pediatr Surg 2004;39:10621065.

15. Makin E, Harrison PM, Patel S, Davenport M. Pancreatic pseudocysts in children: treatment by endoscopic cyst gastrostomy. J Pediatr Gastroenterol Nutr 2012;55:556-558.

16. Breckon V, Thomson SR, Hadley GP. Internal drainage of pancreatic pseudocysts in children using an endoscopically-placed stent. Pediatr Surg Int 2001;17:621-623.

17. Nouira F, Ben Ahmed Y, Sarrai N, Ghorbel S, Jlidi S, Chaouachi B. Pancreatic pseudocyst in children: what is the best therapeutic approach? Arch Pediatr 2011;18:1176-1180.

18. Haluszka 0, Campbell A, Horvath K. Endoscopic management of pancreatic pseudocyst in children. Gastrointest Endosc 2002;55:128-131.

19. Sharma SS, Maharshi S. Endoscopic management of pancreatic pseudocyst in children: a long-term follow-up. J Pediatr Surg 2008;43:1636-1639.

20. Barthet M, Sahel J, Bodiou-Bertei C, Bernard JP. Endoscopic transpapillary drainage of pancreatic pseudocysts. Gastrointest Endosc 1995;42:208-213.

21. Catalano MF, Geenen JE, Schmalz MJ, Johnson GK, Dean RS, Hogan WJ. Treatment of pancreatic pseudocysts with ductal communication by transpapillary pancreatic duct endoprosthesis. Gastrointest Endosc 1995;42:214-218.

22. Kozarek RA. Pancreatic stents can induce ductal changes consistent with chronic pancreatitis. Gastrointest Endosc 1990;36:93-95.

23. Jia Y, Maspons A, Othman MO. The therapeutic use of endoscopic ultrasonography in pediatric patients is safe: a case series. Saudi J Gastroenterol 2015;21:391-395.

24. Grimm H, Binmoeller KF, Soehendra N. Endosonographyguided drainage of a pancreatic pseudocyst. Gastrointest Endosc 1992;38:170-171.

25. Wiersema MJ. Endosonography-guided cystoduodenostomy with a therapeutic ultrasound endoscope. Gastrointest Endosc 1996;44:614-617.
26. Scheers I, Ergun M, Aouattah T, et al. Diagnostic and therapeutic roles of endoscopic ultrasound in pediatric pancreaticobiliary disorders. J Pediatr Gastroenterol Nutr 2015;61:238-247.

27. Jazrawi SF, Barth BA, Sreenarasimhaiah J. Efficacy of endoscopic ultrasound-guided drainage of pancreatic pseudocysts in a pediatric population. Dig Dis Sci 2011;56:902-908.

28. Ramesh J, Bang JY, Trevino J, Varadarajulu S. Endoscopic ultrasound-guided drainage of pancreatic fluid collections in children. J Pediatr Gastroenterol Nutr 2013;56:30-35.

29. Kim W, Jagroop SM, Kayal M, et al. Endoscopic ultrasound guided pancreatic fluid collection drainage in the pediatric population: experience from a single academic medical center. Gastrointest Endosc 2014;79(Suppl 5):AB446.

30. Trevino J, Saeed S, Varadarajulu S. Bedside EUS for management of symptomatic pancreatic fluid collections in critically ill children. Gastrointest Endosc 2010;71(Suppl 5):AB255-AB256.

31. Lakhtakia S, Agarwal J, Gupta R, Ramchandani M, Kalapala R, Nageshwar Reddy D. EUS-guided transesophageal drainage of peripancreatic fluid collections in children. Gastrointest Endosc 2015;82:587-588.

32. Varadarajulu S, Christein JD, Tamhane A, Drelichman ER, Wilcox CM. Prospective randomized trial comparing EUS and EGD for transmural drainage of pancreatic pseudocysts (with videos). Gastrointest Endosc 2008;68:1102-1111.

33. Park DH, Lee SS, Moon SH, et al. Endoscopic ultrasound-guided versus conventional transmural drainage for pancreatic pseudocysts: a prospective randomized trial. Endoscopy 2009;41:842848

34. Shah RJ, Shah JN, Waxman I, et al. Safety and efficacy of endoscopic ultrasound-guided drainage of pancreatic fluid collections with lumen-apposing covered self-expanding metal stents. Clin Gastroenterol Hepatol 2015;13:747-752.

35. Chandran S, Efthymiou M, Kaffes A, et al. Management of pancreatic collections with a novel endoscopically placed fully covered self-expandable metal stent: a national experience (with videos). Gastrointest Endosc 2015;81:127-135.

36. Musumba C, Tutticci N, Nanda K, Kwan V. Endosonographyguided drainage of malignant fluid collections using lumenapposing, fully covered self-expanding metal stents. Endoscopy 2014;46:690-692.

37. Walter D, Will U, Sanchez-Yague A, et al. A novel lumen-apposing metal stent for endoscopic ultrasound-guided drainage of pancreatic fluid collections: a prospective cohort study. Endoscopy 2015;47:63-67.

38. Giefer MJ, Balmadrid BL. Pediatric application of the lumenapposing metal stent for pancreatic fluid collections. Gastrointest Endosc 2016;84:188-189.

39. Nieto J, Koul A, Willingham FF. EUS-guided drainage of pancreatic fluid collections in pediatric patients using a novel fully covered lumen-apposing self expanding metal stent: a multicenter experience. Gastrointest Endosc 2015;81(Suppl 5):AB298. 